\title{
Optimum performance determination of single-stage and dual-stage (contra-rotating) rim driven fans for electric aircraft
}

Bolam, R.C., Vagapov. Y., Laughton, J. and Anuchin, A.

This is a paper presented at the 11th Int. Conf. on Electrical Power Drive Systems (ICEPDS), Saint-Petersburg, Russia, 4-7 Oct. 2020

Copyright of the author(s). Reproduced here with their permission and the permission of the conference organisers.

\section{Recommended citation:}

Bolam, R.C., Vagapov. Y., Laughton, J. and Anuchin, A. (2020), 'Optimum performance determination of single-stage and dual-stage (contra-rotating) rim driven fans for electric aircraft'. In: Proc. 11th Int. Conf. on Electrical Power Drive Systems (ICEPDS), Saint-Petersburg, Russia, 4-7 Oct. 2020, pp. 1-6. doi: 10.1109/ICEPDS47235.2020.9249263 


\section{Optimum Performance Determination of Single-Stage and Dual-Stage (Contra-Rotating) Rim Driven Fans for Electric Aircraft}

\author{
Robert Cameron Bolam \\ Glyndwr University \\ Wrexham, UK \\ Jon Laughton \\ Ad-Manum UAS Technologies Ltd \\ Huddersfield, UK
}

\author{
Yuriy Vagapov \\ Glyndwr University \\ Wrexham, UK \\ Alecksey Anuchin \\ Moscow Power Engineering Institute \\ Moscow, Russia
}

\begin{abstract}
Electrical Rim Driven Fan (RDF) technology is a novel application to aircraft propulsion, and there are many factors that play a part in determining its optimal achievable performance, for example, the electrical, magnetic and thermal properties of the rim driven motor architectures; the mechanical strength, mass and friction properties of the materials used; the aerodynamics of the fans and the efficiency of the motor drive and control circuitries. Each of these factors could easily warrant their own lengthy and indepth analyses. The aims of this paper are to provide a starting point from which to get a feel for the rough-ordermagnitude of an RDFs performance and to elucidate a conventional calculative methodology suitable for a quick and easy reality-check before undertaking more accurate numerical analysis techniques. Initially, the properties of an existing aerospace fan design, namely that of the IAE V2500A5 turbo-fan engine, is used to validate this approach and then the same methodology is used to estimate a first-guess performance prediction for a range of single-stage RDFs of varying sizes from $100 \mathrm{~mm}$ to $500 \mathrm{~mm}$ diameter, operating over a range of speeds from zero to $25 \mathrm{kRPM}$. Finally, a comparison between a single-stage and a dual-stage (contrarotating) $200 \mathrm{~mm}$ diameter RDF for a UAV application is conducted. The performance limits of the RDFs considered in this analysis have been established to ensure that the fan blades are always operating within the subsonic flow regime.
\end{abstract}

Keywords-rim driven fan, RDF, unmanned aircraft, UAV, electric aircraft, specific speed, specific diameter, contrarotating fan

\section{INTRODUCTION}

One of the earliest recorded accounts of rim driven fan technology for aerospace applications took place in 1961 when the Ryan Aircraft Corporation developed the XV-5A Vertifan aircraft. The XV-5A fans were pneumatically driven by jet engine exhaust gasses acting on turbine blades located around the periphery of the aircraft's lift producing fans [1]. Although the fan technology was deemed a success the rim drive element was halted, and the fan design went on to be developed for the General Electric CF6 high by-pass engine designs. The cutaway view of the Ryan XV-5A pneumatically Rim Driven Fans is shown in Fig. 1.

Electrical rim driven fan technology for aircraft applications has also been the subject of various theoretical

This work is funded by the Welsh Government (WEFO) under the SMARTExpertise initiative (Project Reference 82321) and is supported by the European Regional Development Fund. publications since the 1960s, one of the more recent (2006) being conducted at the NASA Glenn Research Centre during which a thirty two-inch $(813 \mathrm{~mm})$ diameter rim driven fan was the subject of an active magnetic (levitated) rim bearing study [2]. However, this study did not consider the performance characteristics of the fan over a range of operational speeds. A more recent account of electrical RDF technology (2017) involved the manufacture and concept demonstration of a plastic, low-cost 3D printable electrical RDF intended for small UAV applications [3]. The study successfully tested the $115 \mathrm{~mm}$ diameter RDF to speeds in excess of 10,000 RPM. However, the fan blades had not been aerodynamically optimised, and the input power and thrust values derived during the test were not considered optimal. Neither did this study consider the performance analysis of other RDF diameters over a range of rotational speeds.

In common with turbo-fan engines, electrical Rim Driven Fans (RDFs) entrain an airflow on which work is done to generate thrust. Although, unlike turbo-fans, this is not achieved by elevating a "core-flow" part of the air to high pressures and temperatures nor by combusting fuels resulting in environmentally damaging gas emissions. Instead, RDFs impart their momentum to the entire airflow using the electromagnetic interaction of the rim motor architecture and resulting fan rotation and as such offer an attractive solution for zero-emission propulsion.

One of the most appealing aspects of electrical RDF technology is the possibility to arrange them in close tandem and energise them to contra-rotate. This benefits the thrust generation of the overall unit by increasing the thrust

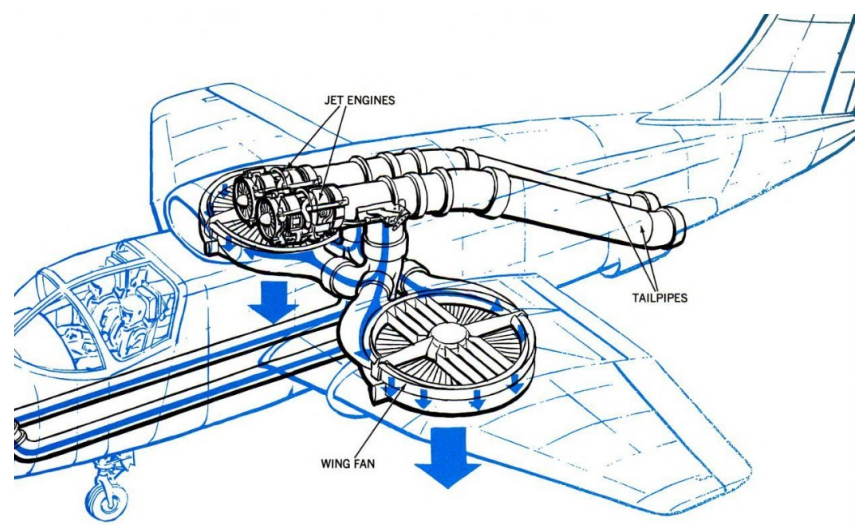

Fig. 1. Cutaway view of the Ryan XV-5A pneumatically Rim Driven Fans [1]. 
per unit frontal area and eliminating the efflux swirl, improving its thrust efficiency. The increased thrust is generated due to an increase in the fan pressure ratio FPR. This paper details a method of estimating the performance of single-stage and dual-stage (contra-rotating) RDFs intended for electrical aircraft propulsion.

\section{Performance Analysis}

The aerodynamic efficiency of the fan blades is considered to significantly degraded as the relative velocity of the air to the fan blade nears the sonic (Mach 1) condition. The fan blade velocity $v$ was determined using:

$$
v=\frac{2 \pi N r}{60}
$$

where $N$ is rotational speed in revolutions per minute $(\mathrm{RPM}) ; r$ is the fan radius.

The speed of sound in air $a$ is mainly dependent on the static air temperature and can be calculated with the following formula:

$$
a=\sqrt{\gamma R T_{o}}
$$

where $\gamma$ is the ratio of specific heat capacities; $R$ is the specific gas constant for air; $T_{o}$ is the static (ambient) temperature.

Under International Standard Atmosphere (ISA) conditions, $\quad \gamma=1.4, \quad R=287 \mathrm{~J} / \mathrm{Kg} \cdot \mathrm{K}, \quad$ and $T_{o}=288 \mathrm{~K}$ $\left(15^{\circ} \mathrm{C}\right)$. Therefore, the speed of sound in air can be calculated as:

$$
a=\sqrt{1.4 \times 287 \times 288}=340 \mathrm{~m} / \mathrm{s}
$$

Table I provides an overview of RDF diameters versus rotational speeds. The shaded areas signify when the RDF would be operating under sonic flow conditions resulting in sub-optimal performance. The performance analysis of the RDFs was conducted for the subsonic operational range of speeds from zero to $30,000 \mathrm{RPM}$ and fan radii from 0.05 to $0.3 \mathrm{~m}$.

A Fan Pressure Ratio (FPR) was first determined based on a design operational fan efflux of $100 \mathrm{~m} / \mathrm{s}$. Therefore, the differential pressure $\Delta p$, across the RDF was estimated using:

$$
\begin{gathered}
\Delta p=\frac{1}{2} \rho v^{2}=0.5 \times 1.225 \times 10000=6125 \mathrm{~Pa} \\
F P R=\frac{p_{o}+\Delta p}{p_{o}}=\frac{101325+6125}{101325}=1.06
\end{gathered}
$$

where $\rho$ is the air density, $\mathrm{kg} / \mathrm{m}^{3} ; p_{o}$ is the static pressure.

Table I. Overview of RDF Diameters versus Rotational Speeds.

\begin{tabular}{|c|c|c|c|c|c|c|}
\hline \multirow{2}{*}{ RPM } & \multicolumn{7}{|c|}{ RDF Diameter (m) } \\
\cline { 2 - 7 } & $\mathbf{0 . 1}$ & $\mathbf{0 . 2}$ & $\mathbf{0 . 3}$ & $\mathbf{0 . 4}$ & $\mathbf{0 . 5}$ & $\mathbf{0 . 6}$ \\
\hline 0 & 0 & 0 & 0 & 0 & 0 & 0 \\
\hline 5000 & 26 & 52 & 79 & 105 & 131 & 157 \\
\hline 10000 & 52 & 105 & 157 & 209 & 262 & 314 \\
\hline 15000 & 79 & 157 & 236 & 314 & 393 & 471 \\
\hline 20000 & 105 & 209 & 314 & 419 & 524 & 628 \\
\hline 25000 & 131 & 262 & 393 & 524 & 655 & 785 \\
\hline 30000 & 157 & 314 & 471 & 628 & 785 & 942 \\
\hline
\end{tabular}

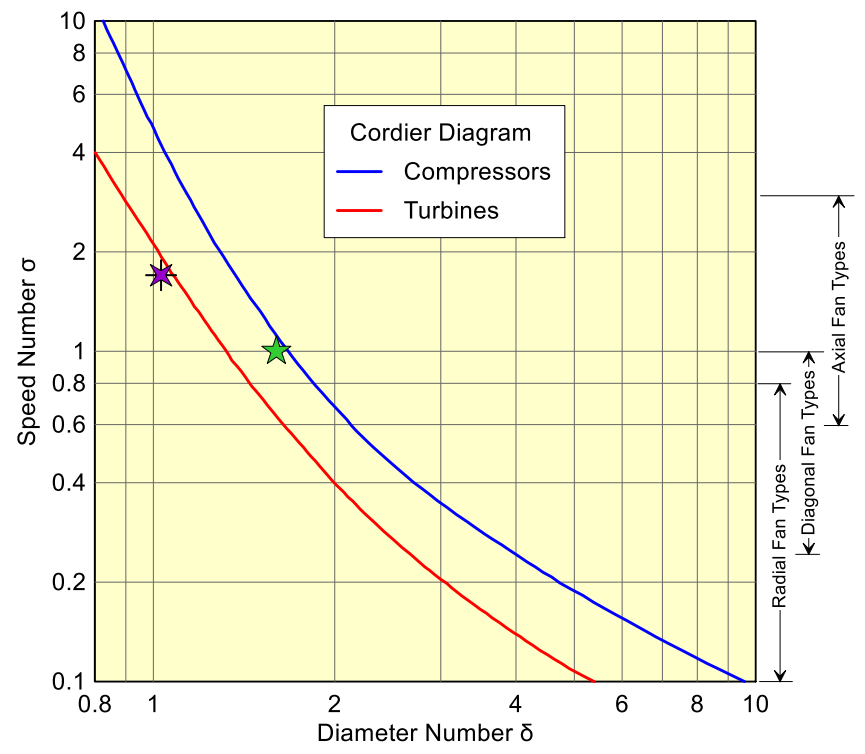

Fig. 2. Cordier Diagram (S/N range 0.06 to 0.8 - Radial Fan Types; $\mathrm{S} / \mathrm{N}$ range 0.25 to 1.0 - Diagonal Fan Ttypes; $\mathrm{S} / \mathrm{N}$ range 0.6 to $3.0-$ Axial Fan Types) [5].

The specific work $(Y) \mathrm{J} / \mathrm{kg}$ is a very useful and versatile parameter in the analysis of turbo-machinery and provides a measure of the work expended by the fan on each kilogram of air. It and can be evaluated by using the following relationships:

$$
\begin{gathered}
Y=\frac{P}{\dot{M}} \\
Y=\frac{\Delta p}{\rho} \\
Y=\Delta C_{w} U \\
Y=C_{p} \Delta T
\end{gathered}
$$

where $M$ is the massflow, $\mathrm{kg} / \mathrm{s} ; \Delta C_{w}$ is the whirl velocity difference, $\mathrm{m} / \mathrm{s} ; U$ is the tangential (whirl) velocity, $\mathrm{m} / \mathrm{s} ; C_{p}$ is the specific heat capacity (of air) at constant pressure (taken as 1005 ) $\mathrm{J} / \mathrm{kg} \cdot \mathrm{K}$.

The Cordier diagram shown in Fig. 2 indicates the optimum wheel types based on two important fan parameters calculated for the design point; The Fan Specific Speed number $(\sigma)$ and the Fan Specific Diameter number $(\delta)$.

The Fan Specific Speed number $(\sigma)$ is a dimensionless fan performance parameter based on the rotational speed of the fan, its volumetric through-flow and the specific work supply to the airflow.

$$
\sigma=n \frac{\sqrt{\dot{V}}}{\left(2 Y_{t}\right)^{\frac{3}{4}}} 2 \sqrt{\pi}
$$

where $n$ is rotational speed in revolutions per second (RPS).

The fan Specific Diameter number $(\delta)$ is also a dimensionless fan performance parameter but is based on the geometry of the fan its volumetric through flow and the specific work supply to the airflow.

$$
\delta=D \sqrt[4]{\frac{2 Y_{t}}{\dot{V}^{2}}} \times \frac{\sqrt{\pi}}{2}
$$

where $D$ is the fan diameter, $\mathrm{m}$. 
By way of example, calculated Speed and Diameter Numbers for a modern high by-pass fan-jet engine are shown in Table II.

For the below tabulated fan specification. The fan specific work Y was first calculated:

$$
Y=\frac{\Delta P}{\rho}=\frac{(1.6 \times 101325)-101325}{1.225}=49628.6 \mathrm{~J} / \mathrm{kg}
$$

The fan Specific Speed Number could then be determined using (10):

$$
\sigma=94.2 \frac{\sqrt{257.5}}{(2 \times 49628.6)^{\frac{3}{4}}} 2 \sqrt{\pi}=0.96 \approx 1
$$

The fan Specific Diameter Number could then be determined using (11):

$$
\delta=1.6 \times \sqrt[4]{\frac{2 \times 49628.6}{257.5^{2}}} \times \frac{\sqrt{\pi}}{2}=1.57 \approx 1.6
$$

The fan air whirl velocity difference was also determined using (8):

$$
\Delta C_{w}=\frac{Y}{U}=\frac{49628.6}{473}=104.9 \mathrm{~m} / \mathrm{s}
$$

and the fan tip speed to whirl velocity ratio was calculated:

$$
\text { Euler }(\text { fan }) \text { ratio }=\frac{\Delta C_{w}}{U}=\frac{104.9}{473}=22 \%
$$

This $22 \%$ "Euler" (whirl velocity based) ratio $\left(\Delta C_{\mathrm{w}} / U\right)$ is a useful indication of the fan blade's ability to transfer energy to the air in relation to the tangential velocity $(U)$ of the blade. The $U$ value of $473 \mathrm{~m} / \mathrm{s}$ is a very high

Table II. Technical Details of V2500-A5 Aircraft Engine Fan.

\begin{tabular}{|l|c|}
\hline \multicolumn{2}{|c|}{ Turbo Fan Engine (Airbus A319, A320, A321) V2500-A5 } \\
\hline Take-off Thrust (N) & 102,480 \\
\hline Dry Weight (Mass) (kg) & 2404 \\
\hline By-pass Ratio & $4.5: 1$ \\
\hline Mass flow rate (kg/s) & 384 \\
\hline Volumetric Flow (ISA conditions) $\left(\mathrm{m}^{3} / \mathrm{s}\right)$ & 313.5 \\
\hline Fan Diameter (m) & 1.6 \\
\hline Fan Pressure Ratio (FPR) & 1.6 \\
\hline LP Shaft Max. Speed (RPM) & 5650 \\
\hline Fan tip-speed (max.) (m/s) & 473 \\
\hline
\end{tabular}

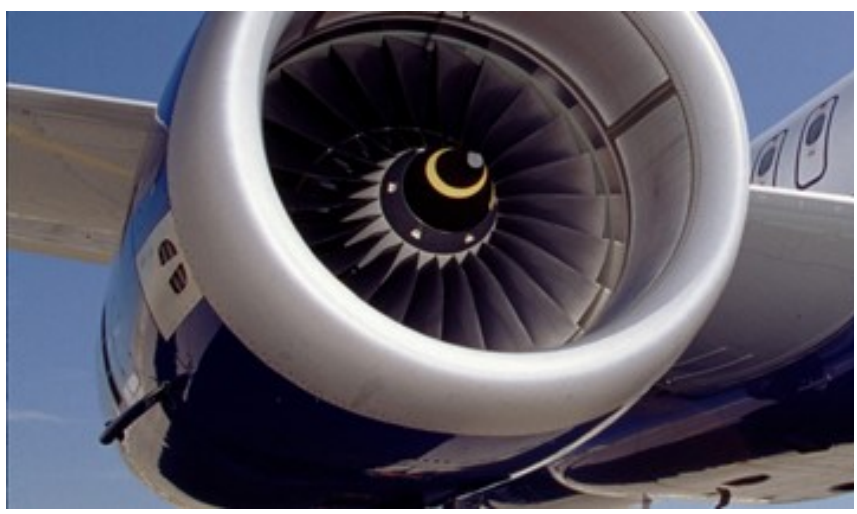

Fig. 3. IAE V2500-A5 aircraft engine fan [4].
Table III. Calculated Performance Values for the V2500-A5 AirCRAFt ENGINE FAN.

\begin{tabular}{|l|l|}
\hline \multicolumn{2}{|c|}{ Turbo Fan Engine (Airbus A319, 320, 321) V2500-A5 } \\
\hline Fan Speed Number & 1 \\
\hline Fan Diameter Number & 1.6 \\
\hline Tip speed to whirl velocity ratio $\left(\Delta C_{w} / U\right)$ & $22 \%$ \\
\hline
\end{tabular}

(supersonic) fan tip speed and the $22 \%$ indicates an excellent proprietary fan blade aerodynamic design. Table III lists the calculated values for the V2500-A5 fan and the five-pointed star marker in Fig. 2 indicates that the fan is positioned close to the optimum performance curve of the Cordier diagram. The V2500 engine Design Point, for optimum efficiency, would normally be the aircraft cruise mode at altitude. However, this basic analysis has shown that even under the assumed ISA Sea Level conditions the fan also performs very well.

\section{InPut (Shaft) Power ReQuirement for Optimum RDF PERFORMANCE}

Equation (8) dictates that small diameter fans must rotate at much higher speeds than large commercial turbofans to achieve the Specific Work input required to generate thrust for propulsion. The following analysis studies Rim Driven Fans of varying diameters between 100 and $500 \mathrm{~mm}$. These fans are considered to operate with optimum performance in the sub-sonic flow regime (refer to Table I). Having a $17 \%$ Euler fan ratio which is representative of the state-of-the-art hub-driven electrical ducted fans (EDFs) used for small unmanned and model aircraft propulsion [6].

The analysis was based on a $17 \%$ Euler fan ratio. Whereby the fan whirl velocity difference $\left(\Delta C_{w}\right)$ is $17 \%$ of the fan tangential tip-speed (U). The difference in whirl velocity is the difference between the fan entry plane whirl $\left(C_{w 1}\right)$ and its exit plane whirl $\left(C_{w 2}\right)$, where:

$$
\Delta C_{w}=C_{w 2}-C_{w 1}
$$

This allowed a specific work value $(Y)$ to be calculated using (8):

$$
Y=\Delta C_{w} U
$$

Assuming International Standard Atmosphere sea-level conditions, (7) was used to calculate values of the fan pressure rise for a range of fan speeds from zero to 25,000 revolutions per minute (RPM):

$$
\Delta p=Y \times \rho
$$

A volumetric flow estimate for the RDF was then calculated based on the fan inlet diameter and assuming a fan flow co-efficient $K_{\text {fan }}=0.95$ :

$$
\dot{V}=K_{f a n} \times \sqrt{\frac{2 \times \Delta p}{\rho}} \times \frac{\pi\left(D_{r i m}^{2}-D_{h u b}^{2}\right)}{4}
$$

A mass flow estimate was calculated using the following relationship:

$$
\dot{M}=\rho \dot{V}
$$

and an input power value determined with the following equation:

$$
P=\dot{M} Y
$$




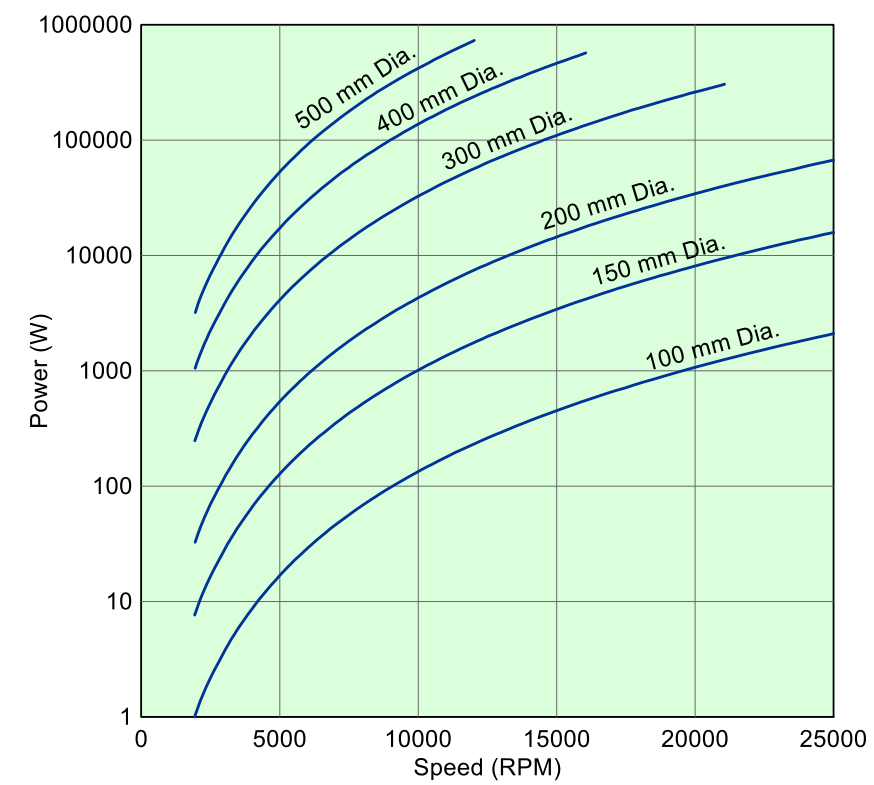

Fig. 4. Single-stage RDF power requirements for a range of inlet diameters.

Table IV. Calculated RDF Performance Values for InPut (Shaft) POWER.

\begin{tabular}{|c|c|c|c|c|c|c|}
\hline \multirow{2}{*}{$\begin{array}{c}\text { Fan } \\
\text { Speed } \\
\text { (RPM) }\end{array}$} & \multicolumn{6}{|c|}{ RDF-Fan Diameter (mm) } \\
\cline { 2 - 7 } & 100 & 150 & 200 & 300 & 400 & 500 \\
\cline { 2 - 7 } & \multicolumn{7}{|c|}{ Optimum RDF Input (shaft) Power (W) } \\
\hline 0 & 0 & 0 & 0 & 0 & 0 & 0 \\
\hline 5000 & 16 & 122 & 512 & 3889 & 16387 & 50010 \\
\hline 10000 & 128 & 972 & 4097 & 31110 & 131099 & 400082 \\
\hline 15000 & 432 & 3281 & 13827 & 104997 & 442458 & \multirow{3}{*}{$\begin{array}{c}\text { Fan- } \\
\text { Flow }\end{array}$} \\
\hline 20000 & 1024 & 7778 & 32775 & 248883 & Sonic \\
\hline 25000 & 2000 & 15191 & 64013 & \multicolumn{4}{|c}{} \\
\hline
\end{tabular}

Table V. Calculated RdF Values for Fan Pressure Ratio (FPR).

\begin{tabular}{|c|c|c|c|c|c|c|}
\hline \multirow{2}{*}{$\begin{array}{c}\text { Fan } \\
\text { Speed } \\
\text { (RPM) }\end{array}$} & \multicolumn{6}{|c|}{ RDF-Fan Diameter (mm) } \\
\cline { 2 - 7 } & 100 & 150 & 200 & 300 & 400 & 500 \\
\cline { 2 - 7 } & \multicolumn{5}{|c|}{ Optimum RDF Fan Pressure Ratio (FPR) } \\
\hline 0 & 1 & 1 & 1 & 1 & 1 & 1 \\
\hline 5000 & 1.001 & 1.003 & 1.01 & 1.01 & 1.02 & 1.04 \\
\hline 10000 & 1.006 & 1.01 & 1.02 & 1.05 & 1.09 & 1.14 \\
\hline 15000 & 1.013 & 1.03 & 1.05 & 1.11 & 1.20 & \\
\hline 20000 & 1.023 & 1.05 & 1.09 & 1.20 & $\begin{array}{c}\text { Sonic } \\
\text { Fan- } \\
\text { Flow }\end{array}$ \\
\hline 25000 & 1.035 & 1.08 & 1.14 & \multicolumn{3}{c}{} \\
\hline
\end{tabular}

The fan pressure ratio $(F P R)$ is the ratio of the fan's input total pressure to its output total pressure and this was derived using the static air pressure value $p_{o}=101325 \mathrm{~Pa}$ :

$$
F P R=\frac{p_{o}+(Y \rho)}{p_{o}}
$$

\section{A. Single Stage RDF Results}

For the range of speeds analysed the Specific Speed and Specific Diameter values for the RDF were determined to be: $\sigma=1.7$ and $\delta=1.03$ using (13) and (14), respectively. These values have been plotted on the Cordier diagram and are indicated by the four-pointed star marker (Fig. 2).
Table Vi.Calculated Performance Values of RDF Static Thrust.

\begin{tabular}{|c|c|c|c|c|c|c|}
\hline \multirow{2}{*}{$\begin{array}{c}\text { Fan } \\
\text { Speed } \\
\text { (RPM) }\end{array}$} & \multicolumn{6}{|c|}{ RDF-Fan Diameter (mm) } \\
\cline { 2 - 7 } & 100 & 150 & 200 & 300 & 400 & 500 \\
\cline { 2 - 7 } Optimum RDF Static Thrust (N) \\
\hline 0 & 0 & 0 & 0 & 0 & 0 & 0 \\
\hline 5000 & 2 & 10 & 30 & 153 & 483 & 1179 \\
\hline 10000 & 8 & 38 & 121 & 611 & 1932 & 4717 \\
\hline 15000 & 17 & 86 & 272 & 1376 & 4348 & \multirow{2}{*}{$\begin{array}{c}\text { Sonic } \\
\text { Fan- } \\
\text { Flow }\end{array}$} \\
\hline 20000 & 30 & 153 & 483 & 2446 & \multicolumn{4}{|c}{} \\
\hline 25000 & 47 & 239 & 755 & \multicolumn{7}{|c|}{} \\
\hline
\end{tabular}

TABle VII. Estimated RDF EfFlux Velocities.

\begin{tabular}{|c|c|c|c|c|c|c|}
\hline \multirow{3}{*}{$\begin{array}{c}\text { Fan } \\
\text { Speed } \\
\text { (RPM) }\end{array}$} & \multicolumn{6}{|c|}{ RDF-Fan Diameter (mm) } \\
\hline & 100 & 150 & 200 & 300 & 400 & 500 \\
\hline & \multicolumn{6}{|c|}{ Optimum RDF Efflux Velocity $(\mathrm{m} / \mathrm{s})$} \\
\hline 0 & 0 & 0 & 0 & 0 & 0 & 0 \\
\hline 5000 & 14 & 21 & 27 & 41 & 55 & 69 \\
\hline 10000 & 27 & 41 & 55 & 82 & 110 & 137 \\
\hline 15000 & 41 & 62 & 82 & 124 & 165 & \\
\hline 20000 & 55 & 82 & 110 & 165 & \multirow{2}{*}{\multicolumn{2}{|c|}{$\begin{array}{l}\text { Sonic } \\
\text { Fan- } \\
\text { Flow }\end{array}$}} \\
\hline 25000 & 69 & 103 & 137 & & & \\
\hline
\end{tabular}

Table VIII. Estimated RDF Mass Flows.

\begin{tabular}{|c|c|c|c|c|c|c|}
\hline \multirow{2}{*}{$\begin{array}{c}\text { Fan } \\
\text { Speed } \\
\text { (RPM) }\end{array}$} & \multicolumn{6}{|c|}{ RDF-Fan Diameter (mm) } \\
\cline { 2 - 7 } & 100 & 150 & 200 & 300 & 400 & 500 \\
\cline { 2 - 7 } Optimum RDF mass flow (kg/s) \\
\hline 0 & 0 & 0 & 0 & 0 & 0 & 0 \\
\hline 5000 & 0.14 & 0.46 & 1.10 & 3.71 & 8.79 & 17.17 \\
\hline 10000 & 0.27 & 0.93 & 2.20 & 7.42 & 17.58 & 34.34 \\
\hline 15000 & 0.41 & 1.39 & 3.30 & 11.13 & 26.37 & \multirow{2}{*}{$\begin{array}{c}\text { Fonic } \\
\text { Fan- }\end{array}$} \\
\hline 20000 & 0.55 & 1.85 & 4.40 & 14.83 & \multicolumn{3}{|c|}{} \\
\hline 25000 & 0.69 & 2.32 & 5.49 & \multicolumn{7}{|c|}{} \\
\hline
\end{tabular}

Fig. 4 shows the performance curves representing the input (shaft) power required to drive the single-stage RDF fans of varying diameters over the range of speeds. And Tables IV-VIII provide the numerical values calculated at interval speeds of 5,000 RPM. By way of example, a $200 \mathrm{~mm}$ diameter RDF operating at 15,000 RPM would be expected to require input supply power to the fan in the order of $13.827 \mathrm{~kW}$. Assuming an electro-magnetic circuit (motor) efficiency of $90 \%$, this would mean an RDF supply power of $15.4 \mathrm{~kW}$. The same diameter fan would provide a fan pressure ratio of FPR 1.05, an efflux velocity in the region of $82 \mathrm{~m} / \mathrm{s}$ and thrust values of around $272 \mathrm{~N}$.

\section{B. Contra-Rotating RDF Results}

As discussed in the introduction section of this paper a two stage contra-rotating $\mathrm{RDF}$ offers the potential for performance improvements over a single-stage RDF for any given fan diameter and rotational speed. The contrarotating fan analysis was based on a $34 \%$ Euler fan ratio. Whereby the fan whirl velocity difference $\left(\Delta C_{w}\right)$ is comprised of $17 \%$ of the fan tangential tip-speed $(U)$ in the 
Table IX.Comparison of Single-Stage and

CONTRA-Rotating RDF Performances.

\begin{tabular}{|l|c|c|}
\hline \multicolumn{2}{|c|}{ Fan Diameter= 200 mm, Fan Speed 15000 RPM } \\
\hline \multicolumn{1}{|c|}{ Parameter } & $\begin{array}{c}\text { Single-Stage } \\
\text { RDF }\end{array}$ & $\begin{array}{c}\text { Contra-Rotating } \\
\text { RDF }\end{array}$ \\
\hline Input Power (Shaft) (kW) & 13.8 & 39.1 \\
\hline Fan Pressure Ratio (FPR) & 1.05 & 1.1 \\
\hline Thrust (N) & 272 & 543 \\
\hline Efflux Velocity (m/s) & 82 & 117 \\
\hline Mass flow (kg/s) & 3.3 & 4.66 \\
\hline
\end{tabular}

clockwise direction and $17 \%$ in the anti-clockwise direction (i.e. $34 \%$ in total). One of the added advantages of the contra-rotating fan arrangement is that the efflux has a minimal, or zero, swirl velocity component further improving the thrust efficiency.

By way of example, Table IX provides a comparison of analysis results for single-stage and contra-rotating RDFs with a $200 \mathrm{~mm}$ diameter RDF operating at $15 \mathrm{kRPM}$.

Fig. 5 and Fig. 6 show the plotted results of the singlestage versus contra-rotating RDF performance comparison over a speed range of zero to $25 \mathrm{kRPM}$.

\section{Discussion}

This analysis provides the estimated performance of single-stage and dual-stage rim driven fans of various inlet diameters over a wide range of speeds. It can be seen that an important limiting factor of larger diameter fans is their tip-speeds. This is because the aerodynamic performance of the fan degrades markedly when the airflow becomes sonic. For example, a $500 \mathrm{~mm}$ diameter fan reaches Mach 1 (sonic velocity) at $13 \mathrm{kRPM}$ under ISA sea level conditions. It was also determined that the input power required to drive an RDF increases with a polynomial relationship in degree five to an increase in the fan diameter. For example, a simple doubling of fan diameter (fan diameter $\times 2^{1}$ ) will require an increase of approximately thirty-two times the input power at the same speed (input power increase $\times 2^{5}$ ). A trebling of the fan diameter (fan diameter $\times 3^{1}$ ) will require an increase of approximately two hundred and forty -three times the input power at the same speed (input power increase $\times 3^{5}$ ). The analysed RDF input-power requirements are presented in the log-linear curves of Fig. 4. The tabulated results also demonstrate how high fan-blade speeds are essential to generating high fan pressure ratios and efflux velocities. In Table VII it can be seen that a $100 \mathrm{~mm}$ diameter RDF operating at 15,000 RPM provides an efflux velocity of $41 \mathrm{~m} / \mathrm{s}$ whilst a $200 \mathrm{~mm}$ diameter RDF operating at the same $15000 \mathrm{RPM}$ provides an efflux velocity of $82 \mathrm{~m} / \mathrm{s}$. Indicating that the efflux velocity varies in direct proportion to the fan diameter for a given RDF rotational speed. This observation concurs with established fan "velocity triangle" vector theory commonly employed to determine fan blade angles [7].

\section{Conclusion}

It was concluded that, although there is marked increase of input power with diameter, there is a lesser increase in efflux velocity. However, there is a marked increase in mass-flow and thrust with diameter which are generated by the relatively small increments in the fan pressure ratio $(F P R)$ values listed in Table V. For example, the $200 \mathrm{~mm}$

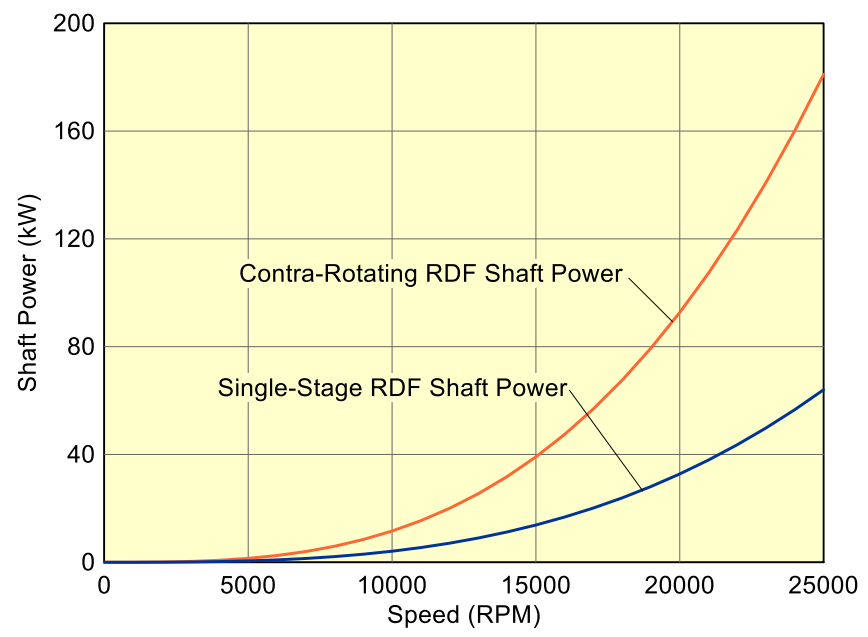

Fig. 5. Comparison of Single-Stage and Contra-Rotating RDF Power Requirements.
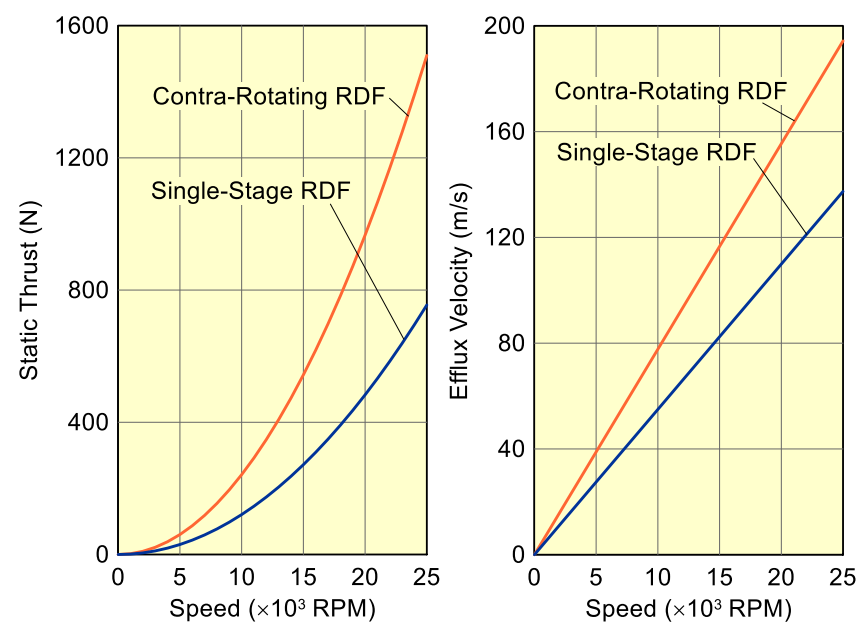

Fig. 6. Comparison of Single-Stage and Contra-Rotating RDF Thrust and Efflux Performances.

RDF operates with an $F P R=1.02$ (at $5 \mathrm{kRPM}$ ) and generates $30 \mathrm{~N}$ of thrust, whereas the same diameter RDF operating with an $F P R=1.05$ (at $15 \mathrm{kRPM}$ ) generates $272 \mathrm{~N}$ of thrust.

An additional effect of increased FPR and the associated rise in total pressure across the fan is an increase in the airflow static temperature; refer to (9). It was concluded that this airflow temperature rise would manifest itself as an RDF inefficiency unless it is minimised and utilised by design. Minimisation can be achieved by ensuring that the design-point fan pressure ratio of the RDF correctly matches the intended aircraft speed as closely as possible and hence maximises the overall propulsive efficiency of the aircraft which is best achieved using aircraft with low drag coefficients. Utilisation can be achieved by careful design of the RDF nozzle section to ensure smooth exhaust air expansion and acceleration to the ambient free-stream conditions. Thus, it was concluded that if an RDF, or indeed any type of electrical ducted fan (EDF), is to be used for high speed subsonic propulsion to match modern commercial turbo-fan aircraft capabilities. It would be important to ensure that the fan and airframe assembly have much improved aerodynamic and operational efficiencies to those of conventional, state-ofthe-art "wing and tube" airframes with large diameter turbofans. In this respect, blended wing-body aircraft and 
distributed thrust propulsion systems [8] offer an attractive solution. Under such circumstances, the installation of multiple dual-stage contra-rotating RDFs could be of benefit. For example, the results of the static performance analysis conducted indicated that a $400 \mathrm{~mm}$ diameter contra -rotating RDF, can provide approximately $8.7 \mathrm{kN}$ of thrust with an efflux velocity $240 \mathrm{~m} / \mathrm{s}$ (Mach 0.7 ) and an $F P R=1.4$. Whilst also offering electric motor drive efficiencies in excess of $90 \%$, with relatively low temperature material operations and zero emissions.

This paper has determined optimum performance parameters applicable to single-stage and contra-rotating rim driven fans (RDFs) that are intended for the electrical propulsion of UAVs. It has also presented an analytical methodology suitable to a first-guess performance prediction for a range of RDFs of varying sizes and over a range of operating speeds. It is intended that future work in this area will concentrate on determining the output (shaft) power performance of aerospace-centred, RDF motor architectures of varying diameters.

\section{REFERENCES}

[1] M. Smith, "VZ-11-VTOL lift from fans in the wings," Flight International, vol. 81, no. 2756, pp.526-527, 27 Sept. 1962.

[2] J.E. Dennis, C.A. Gallo, P.A. Solano, W.K. Thompson, and D.R. Vrnak, "Development of a 32 inch diameter levitated ducted fan conceptual design," NASA Glenn Research Centre, Cleveland, $\mathrm{OH}$ Rep. NASA/TM-2006-214481, Dec 2006.

[3] R. Bolam, and Y. Vagapov, "Implementation of electrical rim driven fan technology to small unmanned aircraft," in Proc. 7th IEEE Int. Conf. on Internet Technologies and Applications ITA-17, Wrexham, UK, 12-15 Sept. 2017, pp. 35-40.

[4] IAE International Aero Engines. (2020). Products. [Online]. Available: http://i-a-e.com/products.html

[5] W. Bohl, Ventilatoren: Berechnung, Konstruktion, Versuch, Betrieb Wurzburg: Vogel, 1983.

[6] Schuebeler Technologies. (2020). [Online]. Available: http:// schuebeler-technologies.de/en/

[7] H.I.H. Saravanamuttoo, G.F.C. Rogers, H. Cohen, P.V. Straznicky, and A. Nix, Gas Turbine Theory, 7th ed. Harlow: Pearson Prentice Hall, 2017.

[8] H.D. Kim, J.L. Felder, M.T. Tong, J.J. Berton, and W.J. Haller, "Turboelectric distributed propulsion benefits on the N3-X vehicle," Aircraft Engineering and Aerospace Technology, vol. 86, no. 6, pp. 558-561, Sept. 2014. 